\title{
Outcome of Ileostomy in the Management of Ileal Perforation
}

\author{
Faisal Ghani Siddiqui, Jan Mohammad Shaikh, Abdul Ghani Soomro, Karim B ux, \\ Abdul Sattar Memon and Syed Asad Ali
}

\begin{abstract}
OBJECTIVE: To evaluate the role of a defunctioning ileostomy in the prevention of morbidity and mortality in patients with small bowel perforation.

DESIGN: A prospective randomized study.

PLACE AND DURATION OF STUDY: Department of Surgery, Liaquat University of Medical \& Health Sciences, Jamshoro I Hyderabad between October 2005 and September 2006.

SUBJECTS AND METHODS: Total 108 patients who underwent laparotomy for ileal perforation were included.

RESULTS: There were 67 males and 41 females. The age of patients ranged from 15 to 72 years with $80 \%$ of the patients being in age group of 17-70 years. Typhoid was the commonest cause for ileal perforation which was seen in $69(63.8 \%)$ patients, followed by intestinal tuberculosis which was present in $23(21.3 \%)$ patients. Out of a total of 108 patients, a proximal defunctioning ileostomy was constructed to protect the primary repair or the intestinal anastomosis in $\mathbf{5 7}$ patients (group I). In the remaining 51 patients, primary repair or intestinal anastomosis was done without a defunctioning ileostomy (group II). Two (3.5\%) patients in group I and 7 (13.7\%) patients in group II died postoperatively. Six of the $\mathbf{5 1}$ patients in group II who underwent primary closure of perforation or resection and end-to-end anastomosis without a defunctioning ileostomy developed postoperative faecal fistula. None of the patients with defunctioning ileostomy developed this complication.

CONCLUSION: We conclude that construction of a temporary ileostomy to provide defunctioning for repair of ileostomy perforations reduce the incidence of fatal complications like faecal fistula. lleostomy, however, is associated with a number of ileostomy-specific complications. We recommend that defunctioning ileostomy should be preferred over all other surgical options in cases of ileal perforations.
\end{abstract}

KEY WORDS: Ileostomy. Faecal fistula. Ileal perforation. Primary closure. End-to-end anastomosis.

\section{INTRODUCTION}

Ileal perforation is a frequently encountered surgical emergency in developing countries. ${ }^{1,2}$ Typhoid is the most common cause for this dreaded complication; tuberculosis, trauma and non-specific enteritis follow a close suit. ${ }^{3}$ The disease has an abrupt onset and a rapid downhill course with a high mortality if not treated. ${ }^{4}$ Though surgery is accepted as the definite treatment, the choice of exact surgical procedure remains controversial. Most series reporting simple closure of the perforation or resection and anastomosis, in case of multiple perforations, report satisfactory results. ${ }^{5,6}$ This procedure though appears appealing, especially in an emergency setup, it is not free of complications. Of all the postoperative complications reported, faecal fistula remains the most life threatening; the rate of its occurrence has been reported to be around $12 \%$ with a very high mortality rate ${ }^{7}$. In view of this alarming situation, a shift in favour of a defunctioning ileostomy following primary closure of the perforation has been observed in the recent years. The ileostomy protects the intestinal repair done in septic tissues and serves to reduce the risk of postoperative anastomotic dehiscence. ${ }^{8}$ The present study was conducted to assess the efficacy of a defunctioning ileostomy in the prevention of postoperative faecal fistulae in patients with ileal perforation.

\section{PATIENTS AND METHODS}

We report a prospective study of 180 patients who underwent laparotomy for ileal perforation at Liaquat University Hospital, Hyderabad/Jamshoro between October 2005 and September 2006. All the patients in this series initially presented to the casualty department as cases of acute abdomen. On the bases of 
history and physical examination, a provisional diagnosis of intestinal perforation was made. All patients were actively resuscitated and started on IV. Ampiclox and Metronidazole together with a third generation cephalosporin, available in this public sector hospital. Ultrasound abdomen, x-ray chest, and x-ray abdomen were done in all patients. Investigations to assess the cardiopulmonary and renal functions were also carried out. With the confirmation of the initial diagnosis of intestinal perforation, an emergency laparotomy was planned in all cases. Forty percent of the patients underwent laparotomy within the first 24 hours of the admission. Thirty-four percent of the cases were operated after 24 but before 48 hours while rest of the laparotomies were carried out beyond 48 hours. The delay in the surgery was attributable to a myriad of causes such as delayed referral of the patients from the rural health centres, patient's initial refusal to undergo surgery and delay in the availability of blood due to the nonavailability of the patient's relatives. At laparotomy, the peritoneal cavity was invariably found contaminated with faecal matter, pus and blood (in traumatic cases). Eighty-one (75\%) patients had a single perforation with double perforation in 21 $(19.5 \%)$ cases and more than 2 perforations in 6 (5.5\%) cases. Out of a total of 108 patients, a proximal defunctioning ileostomy was constructed to protect the primary repair or the intestinal anastomosis in 57 patients (group I). In the remaining 51 patients, primary repair or intestinal anastomosis was done without a defunctioning ileostomy (group II). The selection of the patients for either of the procedure was done randomly by the flip of the coin. Patients under 12 years of age and those in whom the cause of acute abdomen was other than ileal perforation were excluded from the study. Biopsies from the edge of the perforation were taken in all but the traumatic cases and were sent for histopathology. A thorough peritoneal lavage with 2-3 litres of normal saline was performed before placing drains and closing the wound either as mass closure or in layers depending upon the operator's choice. All the loop ileostomies were done by a standard technique in the right lower quadrant of the abdomen. In 7 patients, the perforations itself were exteriorized as ileostomy. Three patients had to be shifted to the ICU postoperatively in view of their moribund condition. Rest were nursed in the surgical ward. All patients were followed for postoperative complications. The data of the patients wre collected on a specially designed proforma. The results were finally compared and concluded on SPSS version 10.

\section{RESULTS}

There were 67 (62\%) males and 41 (38\%) females. The age of the patients ranged from 15 to 72 years. The two groups were well matched for baseline clinical characteristics such as age, gender ratio and diagnosis Table I. The presenting symptoms in groups I and II respectively included: abdominal pain $100 \%$ and $100 \%$; vomiting $77 \%$ and $80 \%$ and constipation $82 \%$ and $74 \%$. Abdominal distension was present in $81 \%$ and $79 \%$ and abdominal tenderness in $80 \%$ and $76 \%$ of the patients. Seventy-two percent of patients had features of dehydration and $26 \%$ and $21 \%$ of patients had a low blood pressure at the time of admission. Hematological investigations revealed that majority of patients (87\%) were anemic with hemoglobin level less than $10 \mathrm{~g} / \mathrm{dL}$. Other biochemical abnormalities are depicted in Table II. Fewer patients in group I had evidence of gas under diaphragm but this finding was not satisfactorily significant (34 of 57 patients compared to 40 of 51 patients). Eighty-one (75\%) patients had a single perforation, 21 (19.5\%) patients had two while $6(5.5 \%)$ patients had more than two perforations. In $65 \%$ cases, the perforations were situated within $30 \mathrm{~cm}$ from ileocaecal junction with majority (62\%) involving the antimesenteric border. The etiology of perforations in 108 patients is depicted in Table III. Postoperative complications were observed in 89 patients. The mean hospital stay was 30 days, ranging from 14 to 56 days. Morbidity is detailed in Table IV. Two (3.5\%) patients in group I and 7 (13.7\%) patients in group II died postoperatively. Six of the 51 patients in group II who underwent primary closure of perforation or resection and end-to-end anastomosis without a defunctioning ileostomy developed postoperative faecal fistula. This, in majority of the cases was associated with intra-abdominal abscess, leading to a high mortality rate in this group. None of the patients with defunctioning ileostomy developed this complication. Ileostomy related complications such as skin excoriation (87.7\%), ileostomy diarrhea $(68.4 \%)$, ileostomy prolapse (10.5\%) and ileostomy retraction (3.5\%) were, however, the main causes of morbidity and delayed hospital discharge in this group.

TABLE I:

PATIENT CHARACTERISTICS

\begin{tabular}{|l|c|c|}
\hline \multicolumn{1}{|c|}{ Characteristics } & $\begin{array}{c}\text { Group I } \\
(\mathbf{n = 5 7 )}\end{array}$ & $\begin{array}{c}\text { Group II } \\
(\mathbf{n = 5 1 )}\end{array}$ \\
\hline Sex ratio (male: female) & $36: 21$ & $31: 20$ \\
\hline Median age (years) & $33-64$ & $30-70$ \\
\hline
\end{tabular}


Faisal Ghani Siddiqui, Jan Mohammad Shaikh, Abdul Ghani Soomro, et al.

BIOCHEMICAL ABNORMALITIES
\begin{tabular}{|l|c|c|}
\hline $\begin{array}{c}\text { Biochemical } \\
\text { Tests }\end{array}$ & Group I (n=57) & Group II (n=51) \\
\hline Blood urea & $18(32 \%)$ & $15(29 \%)$ \\
\hline Normal & $39(68 \%)$ & $26(71 \%)$ \\
\hline Raised & $46(81 \%)$ & $47(92 \%)$ \\
\hline Serum creatinine & $04(8 \%)$ \\
\hline Normal & $11(19 \%)$ & $25(45 \%)$ \\
\hline Raised & $19(33 \%)$ & $31(55 \%)$ \\
\hline Widal test & $38(67 \%)$ & $31(60 \%)$ \\
\hline Negative & $35(61 \%)$ & $10(40 \%)$ \\
\hline Positive & $22(39 \%)$ & \\
\hline Serum electrolytes \\
\hline Normal
\end{tabular}

TABLE III:

HISTOPATHOLOGICAL DATA $(n=108)$

\begin{tabular}{|l|c|c|}
\hline Histopathology & Group I (n=57) & Group II (n=51) \\
\hline Typhoid & $38(66 \%)$ & $31(60 \%)$ \\
\hline Tuberculosis & $12(21 \%)$ & $11(22 \%)$ \\
\hline $\begin{array}{l}\text { Non-specific } \\
\text { inflammation }\end{array}$ & $05(9 \%)$ & $02(4 \%)$ \\
\hline Trauma* & $02(4 \%)$ & $07(14 \%)$ \\
\hline
\end{tabular}

*No biopsies done

\section{DISCUSSION}

Spontaneous ileal perforation remains a formidable surgical condition in developing countries. Typhoid fever is the predominant cause of non-traumatic ileal perforation while other common causes include tuberculosis and trauma. ${ }^{9-11}$ In a series of 170 patients of ileal perforation by Muneer et al, typhoid and tuberculosis were found to be the leading causes with an incidence of $60 \%$ and $14.7 \%$ cases respectively. ${ }^{12}$ Our study confirms findings of similar studies. In this series, typhoid and tuberculosis were the underlying causes of ileal perforation in $68.5 \%$ and $21.3 \%$ respectively. We had a slight male preponderance in our series, with a male to female ratio of 1.6:1. This has been corroborated by other studies. ${ }^{3,13}$ Contrary to the common belief, the incidence of radiological evidence

TABLE IV:

\section{POSTOPERATIVE COMPLICATIONS AND} MORTALITY

\begin{tabular}{|l|c|c|}
\hline & $\begin{array}{c}\text { *Group I } \\
\text { (n=57) }\end{array}$ & $\begin{array}{c}{ }^{* *} \text { Group II } \\
\text { (n=51) }\end{array}$ \\
\hline Wound infection & 50 & 14 \\
\hline Wound dehiscence & 17 & 10 \\
\hline Septicemia & 13 & 04 \\
\hline Intestinal obstruction & 06 & 02 \\
\hline Intra-abdominal abscess & 01 & 04 \\
\hline Faecal fistula & 00 & 06 \\
\hline $\begin{array}{l}\text { Ileostomy related complica- } \\
\text { tions }\end{array}$ & 51 & 00 \\
\hline Death & 02 & 07 \\
\hline
\end{tabular}

* Primary closure / resection and end-to-end anastomosis with defunctioning ileostomy.

** Primary closure / resection and end-to-end anastomosis without defunctioning ileostomy

of pneumoperitoneum was very low, found in only $68.5 \%$ cases in this series, a finding supported by Ajao. ${ }^{14}$ The precise reason for this low occurrence is not known but adhesions around the perforation, sealing of perforation and reabsorption of gases due to delayed presentation can be cited as few causes. Some studies, however, report a higher incidence of gas under diaphragm with a range from 75 to 82.5 percent. ${ }^{3,15,16}$ That ileal perforation is best treated by surgery is universally accepted, but the exact nature of the surgical procedure remains controversial to date. Surgery for ileal perforation is associated with a high morbidity. Of all the postoperative complications, faecal fistula remains the most dreaded with an incidence of around 12 percent. ${ }^{17}$ Anastomotic leakage or dehiscence of the primary repair of the perforation is by far the most frequent underlying cause for the fistula formation. Nguyen reported 5 cases of faecal fistula of his own experience that resulted in 4 deaths and cited Meirer who experienced 6 deaths in 8 cases of postoperative faecal fistula ${ }^{18}$ Kouame et al, have attributed $11(50 \%)$ deaths in their series to faecal fistula. This complication, though not specific to a given surgical technique, nevertheless is seen more commonly when a suture is applied in a septic technique. Kouame et al, report a higher incidence of postoperative fistula in cases where no defunctioning ileostomy was carried out; they report 11 postoperative 
faecal fistula with 8 occurring after end-to-end anastomosis compared to three where resection and anastomosis was protected by a defunctioning ileostomy. ${ }^{10}$ Singh et $a l,{ }^{9}$ in a study of 42 patients undergoing surgery for typhoid perforation found that none of the patients undergoing temporary ileostomy developed a postoperative faecal fistula compared to 5 patients, who developed this complication following simple closure of the perforation. ${ }^{9}$ This study also substantiates these findings. Faecal fistula developed in 6 out of the $51(11.6 \%)$ patients in group II where no defunctioning ileostomy was done to protect the closure of perforation or end-to-end anastomosis. None of the Group I patients with a defunctioning ileostomy developed a faecal fistula. All patients with faecal fistula succumbed causing $13.7 \%$ mortality in group II compared to $3.5 \%$ mortality in group I. The rate of occurrence of faecal fistula is around $12 \%$ and it is widely reported as inducing a high mortality rate. In our own experience, there were 6 deaths in 7 cases of faecal fistula. Postoperative septic shock was the cause of death in the remaining three cases who died in this series. The management of an ileal stoma, however, remains an intimidating task especially in public sector hospitals with no arrangement for stoma-care teams. In our study $87.7 \%$ patients with an ileostomy developed ileostomy-specific complications such as skin excoriation (87.7\%), ileostomy diarrhea (68.4\%), ileostomy prolapse $(10.5 \%)$ and retraction of ileostomy (3.5\%). Two (3.5\%) patients with ileostomy died compared to $7(13.7 \%)$ patients who underwent primary closure or resection and anastomosis without a covering ileostomy. However, though a small number of ileostomy complications were fatal, they caused prolongation of the hospitalization time up to 56 days. A defunctioning ileostomy has firmly been established as a successful procedure in our series in terms of overall mortality. The complications, though, remained very high mainly due to improper fashioning of the stoma and inadequate postoperative nursing care of the stoma.

\section{CONCLUSION}

We conclude that temporary defunctioning ileostomy in cases of ileal perforation plays an important role in reducing the incidence of complications like faecal fistula. This helps reduce mortality in patients undergoing surgery for ileal perforations. Ileostomy-specific complications, however, increase the postoperative stay of the patient. These complications can be reduced, if not outright eliminated, by proper fashioning of the stoma and provision of adequate nursing care of the stoma. We recommend that defunctioning ileostomy should be preferred over all other surgical options in cases of ileal perforations.

\section{REFERENCES}

1. Rehman A. Spontaneous ileal perforation: an experience of 33 cases. J Pak Med I 2003; 3(1): 105-10.

2. Jhobta RS, Attri AK, Kaushik R, Sharma R, Jhobta A. Spectrum of perforation peritonitis in India -review of 504 consecutive cases. World J Emerg Surg 2006; 1: 26.

3. Hussain T, Alam SN, Salim M. Outcome of ileostomy in cases of small bowel perforation. Pak J Surg 2005; 21(2)65-71.

4. Gibney EJ. Typhoid perforation. Br J Surg 1989; 76: 887-9.

5. Richens J. Management of bowel perforation in typhoid fever. Trop Doct 1991; 21: 149-51.

6. Na'aya HU, Eni UE, Chama CM. Typhoid perforation in Maiduguri, Nigeria. Ann of Af Med 2004; 3 (2): 69-72.

7. Talwar S, Sharma R, Mittal DK, Parassad P. Typhoid enteric perforation. Aust N Z J Surg 1997; 67: 351-3.

8. Khan AA, Khan IR, Najeeb U, Shaikh AJ. Comparison between primary repair and exteriorization in cases of typhoid perforation. Ann King Edward Med Coll 2005; 11(3): 226-7.

9. Singh S, Singh K, Grover AS. Two-layer closure of typhoid ileal perforations: a prospective study of 46 cases. Br J Surg 1995; 82: 1253-5.

10. Kouame J, Koudio L, Tarquin HT. Typhoid ileal perforation: surgical experience of 64 patients. Acta Chir Belg 2004; 104: 445-7.

11. Cristopher MP, Tran TH, Gordon D. Typhoid fever. N Engl J Med 2002; 347(22): 1770-82.

12. Muneer A, Shaikh AR, Shaikh GA, Qureshi GA. Various complications in ileostomy construction. World Appl Sci J 2007; 2(3): 190-3.

13. Khanna AK, Misra MK. Typhoid perforation of the gut. Postgr Med J 1984; 60: 523-8.

14. Ajoa OG. Typhoid perforation: factors effecting mortality and morbidity. Int Surg 1982; 67: 317-9.

15. Shirazi B, Shamim MS, Bhatti Al, Shamim M. Localised small bowel perforation -a radiological rarity. J Pak Med Assoc 2005; 54(2): 102-4.

16. Shukla VK, Sahoo SP, Chauhan VS, Pandey M, Gautam A. Enteric perforation -single layer closure. Dig Dis Sci 2004; 49(1): 161-4. 
17. Akung V, Ferry B, Boylu S, Aban N, Tacyildiz I. Typhoid enteric perforation. Br J Surg 1995; 82: 1512-5.
18. Nguyen S. Typhoid perforations in a tropical environment. J Chir 1994; 131: 90-5.

AUTHOR AFFILIATION:

Dr. Faisal Ghani Siddiqui (Corresponding Author)

Assistant Professor of Surgery

Liaquat University of Medical \& Health Sciences,

(LUMHS) Jamshoro, Sindh-Pakistan.

E-mail: fgsiddiqui@gmail.com

\section{Dr. Jan Mohammad Shaikh}

Assistant Professor of Anaesthesia

LUMHS Jamshoro, Sindh-Pakistan.

Dr. Abdul Ghani Soomro

Senior Registrar Surgery

LUMHS Jamshoro, Sindh-Pakistan.

Dr. Karim Bux

Postgraduate Student

Department of Surgery

LUMHS Jamshoro, Sindh-Pakistan.

\section{Dr. Abdul Sattar Memon}

Professor of Surgery

LUMHS Jamshoro, Sindh-Pakistan.

Dr. Syed Asad Ali

Assistant professor of Surgery

LUMHS Jamshoro, Sindh-Pakistan. 